\title{
Beyond human boundaries: variations of human transformation in science fiction
}

\begin{abstract}
Science Fiction is a literary genre of technological changes in human and his life; and is full of imaginative and futuristic concepts and ideas. One of the most significant aspects of Science Fiction is human transformation. This paper will present, firstly, an overview on the history of Science Fiction and some of the most significant sci-fi stories, and will also explore the elements of human transformation in them. Later, it will explain the term of transhumanism as a movement which follows several transformation goals to reach immortality and superiority of human through advanced technology. Next, the views by a number of prominent transhumanists will be outlined and discussed. Finally, three main steps of transhumanism, namely transhuman, posthuman, and cyborg, will be described in details through notable scholars' views in which transhuman will be defined as a transcended version of human, posthuman as a less or non-biological being, and cyborg as a machine human. In total, this is a conceptual paper on an emerging trend in literary theory development which aims to engage critically in an overview of the transformative process of human by technology in Science Fiction beyond its current status.
\end{abstract}

Keyword: Science fiction; Transformation; Transhumanism; Transhuman; Posthuman; Cyborg 